\title{
Virtual reality for older users: a systematic literature review
}

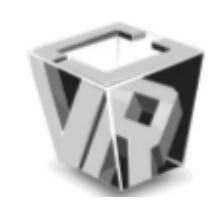

\author{
Rômulo Santos Silva ${ }^{1}$, Artur Martins Mol $^{1}$, Lucila Ishitani $^{1}$ \\ ${ }^{1}$ Programa de Pós-graduação em Informática - Instituto de Ciências Exatas e Informática (PUC Minas) - Belo Horizonte - \\ Brazil
}

Abstract - The use of technologies by the elderly is still restricted, especially concerning recent technologies. To better understand the older user experience, while using virtual reality technology, we performed a Systematic Literature Review. The databases selected for research were the digital libraries of ACM, IEEE, Science Direct and Google Scholar. During the literature review, we collected information about the characteristics of the participants of the studies selected, the experiences reported about the use of technology, the research method used, the technologies chosen for the tests, the results obtained and future work suggested. The main contributions of this work were to identify the state of art of virtual and augmented reality for older people, the possible applications of these technologies to them, the most used devices and also the considerations reported by previous experiences.

Index Terms - virtual reality; older people; systematic literature review; user experience.

\section{INTRODUCTION}

Information and Communication Technologies (ICT) are impacting people's daily lives. There are cell phones, computers, bank terminals, payment boxes for parking in shopping centers among many others. Over the years, the number of technological options continues to grow. This is the case of Virtual Reality (VR) technology, which today allows people to have a new experience and to visit a different place with the use of smartphones, computers, or devices that resemble glasses.

This positive characteristic of VR is especially important for the older people, since many of them find it difficult to travel. Besides, the elderly is an audience that usually has less contact with ICT and at same time they suffer a decline of their physical and cognitive skills. VR technology is an option to help them in daily activities, to keep them up to date and to provide them the opportunity to have fun. For this, it's important to identify design elements and understand more about their VR experience in order to make virtual reality more suitable for them.

So, the purpose of this article is to present the results of a systematic literature review about user experience, research

\footnotetext{
E-mail: rsantos.santos201@gmail.com, amol@pucminas.br, lucila@pucminas.br
}

methods and suggestions of future work considering studies which were already performed with the use of virtual reality technology by older users.

This paper is organized as follows: in Section 2 we described some main characteristics of older people and also main concepts about user experience. Section 3 presents details about the adopted method of systematic literature review. Section 4 shows a quantitative summary of the search results. Section 5 highlights some answers to the research questions, and, finally, Section 6 presents the main conclusions about the results obtained.

\section{BACKGROUND}

In this section we will present some characteristics of the audience of this study and fundamentals of user experience. Knowing characteristics of older people is important for evaluating if their needs are considered in the development of applications for them and also in the conduction of studies with their participation.

\section{Aging-related physical impairments}

People suffer changes during their lives. During old age, people face loss of their physical and cognitive abilities ( $\mathrm{Pa}$ palia and Feldman 2013).

The physical capacities that are reduced with aging are usually related to vision, hearing, motor control and dexterity.

Reduction of visual acuity is perhaps the best known impairment among the elderly problems. Other visual restrictions include the inability to focus on objects that are close (Vasconcelos et al. 2012), serious diseases such as glaucoma and cataract (NCBI 2014), reduced field of vision, reduced colour, depth and contrast perception, decreased adjustment to the dark (Ijsselsteijn et al. 2007; NCBI 2014). Because of that, it is difficult for the elderly to perceive and locate small elements on the screen (LopezMartinez et al. 2011) and to read text with small letters.

Concerning hearing impairments, many older people suffer from presbycusis, or reduced ability to hear sounds at very high frequency, which, for example, makes difficult listening to sounds of beeps (Vasconcelos et al. 2012). "Worldwide, more than 180 million people older than 65 years have hearing loss that interferes with understanding normal conversational speech" (World Health Organization 2015). 
Ageing is also related with muscle mass decline, changes in bones mass, and strength decline. All these changes increase the risk of fracture. "Hip fractures are a particularly devastating type of osteoporotic fracture, and as a result of population ageing they will become more common, reaching an estimated annual global incidence of 4.5 million in 2050" (World Health Organization 2015).

Falls are another problem for the elderly. "Various reviews and meta-analyses have estimated that $30 \%$ of people older than age 65 , and $50 \%$ of people older than age 85 , who live in the community will fall at least once each year. Falls are, in fact, the main risk factor for fractures" (World Health Organization 2015).

Balance control maintains the body's center of gravity on the basis of support during static and moving situations. It is up to the body systems to respond to variations in the center of gravity, either voluntarily or involuntarily. This natural process occurs effectively, mainly by the action of the visual, vestibular and somatosensory systems. With aging, these systems are affected and postural control may be ineffective in dealing with situations, thus reducing the compensatory capacity of the system, leading to increased instability (Maciel 2005).

In 2012, the top 10 health conditions associated with disability, in populations aged 60 years and older were (World Health Organization 2015): hearing loss, back and neck pain, chronic obstructive pulmonary disease, depressive disorders, falls, diabetes mellitus, Alzheimer's disease and other dementias, refractive errors, osteoarthritis, cataract.

\section{Aging-related cognitive impairments}

"Not all cognitive functions deteriorate with age, and language features, such as comprehension, reading and vocabulary, in particular, remain stable throughout life" (World Health Organization 2015). However, in general, the aging process also causes cognitive constraints such as the reduction of attention to details and also of short-term memory (Lopez-Martinez et al. 2011; Vasconcelos et al. 2012).

The reaction response time also increases and this, together with reduction of psychomotor skills, such as motor coordination, makes difficult actions that require a lot of precision (Vasconcelos et al. 2012).

Another problem that older people face is the natural decline of their spatial cognition, even if they are healthy. This "human capacity of orienting oneself in and to cope with everyday environments" impacts on "the capacity to explore new environments, execute way finding in familiar contexts and use landmark for orienting themselves in complex situations"(Morganti et al. 2009).

These impairments can be even worse, especially in case of some diseases, such as dementia and Alzheimer.

Despite all these difficulties, older people often wish to expand their skills and to have interesting options of leisure (Papalia and Feldman 2013). These possibilities can help them to slow down the impact of aging on their physical and cognitive abilities, which often determines their emotional state.

\section{User experience}

As one of the research questions of this study addresses the experience of older users while using virtual reality, it is important to discuss the concept of user experience.

There are many different definitions of User eXperience (UX). ISO 9241-210 defines UX as “a person's perceptions and responses that result from the use or anticipated use of a product, system or service". In UX, perceptions and responses can be presented in different aspects, each representing different characteristics of the user experience such as usability, emotion, engagement and flow (Tcha-Tokey et al. 2016).

One of the main goals of interaction design is to reduce the negative aspects of the user experience, such as frustration and annoyance, while at the same time improving aspects such as fun, commitment, loyalty and trust.

The aspects that affect the user experience can be categorized into four types (Zarour and Alharbi 2017). The first type is user needs, which can be pragmatic (related to usability) or hedonic (related to stimulation). The second type is the brand, which is related to marketing and communication between the user and the organization. The third is the technological aspects, that is the development and production of technologies that impact the experience. Finally, the context includes any property that is not related to one of the previous aspects, but also impacts the experience (Zarour and Alharbi 2017).

Another important feature in user experience studies is evaluation metrics. In order for a coherent identification of perceptions and evaluations, it is necessary to use metrics that allow a parameterized evaluation to make an equivalent review of all responses resulting from the process (Tullis and Albert 2008).

There are several metrics that can be used, among them, some reveal aspects about the user experience or about the personal experience of the human being using a product or service. For instance, a usability metric reveals something about the interaction between the user and a product, bringing the aspect of effectiveness or efficiency to complete a task or the degree of users satisfaction concerning their experience in performing a task. As people are very diverse and adaptable, sometimes the challenge of choosing or using metrics can be great (Tullis and Albert 2008).

\section{METHOD}

The systematic literature review was conducted in order to identify studies and their results related to older user experience while using virtual reality.

Based on the guidelines proposed by (Kitchenham and Charters 2007), we performed the following activities: specifying the research questions, setting of a search strategy, selection of primary studies, assessment of study quality, data extraction and monitoring, data synthesis. These activities are detailed in the next subsections, except the last one, which is detailed in Section 4. 


\section{Research questions}

For this study, three research questions were defined. The first and second ones have three and two specific questions, respectively, as follows:

RQ 1 Which are the characteristics of the studies about the use of virtual reality by older users?

SQ 1.1 What are the objectives of the studies?

SQ 1.2 What were the data analysis procedures?

SQ 1.3 Which virtual reality technology was applied?

RQ 2 How VR impacts on the experience of older users?

SQ 2.1 What design characteristics should be considered for this target audience?

SQ 2.2 What was the experience of the older users regarding the use of VR?

RQ 3 What are the suggestions for future work?

\section{Search strategy}

The research began in December 2018. Because VR is recent technology, no publication date restriction was set.

The major search terms were "virtual reality"and "VR", together with "older users" and similar terms, such as: elderly, senior, older people, older adult, old people, old person, old adult. This resulted in the following search string: "("virtual reality" or "VR") and ("older users" or "elderly" or "senior" or "older people", "older adult" or "old people" or "old person" or "old adult")".

These terms were looked at in the abstract of articles published in the digital libraries of ACM Digital library, IEEE Digital Library, Science Direct and Google Scholar.

\section{Selection of primary studies}

The inclusion criteria were:

- article must be written in English or Portuguese;

- article must present the results of a study involving older users (60 years or more) while using virtual reality technology.

The exclusion criteria were:

- duplicate articles - when similar articles were published in more than one source, it was considered the most recent or most complete one;

- literature reviews, because they do not detail the characteristics of a specific study and therefore they go against the inclusion criterion.

The selection process was based on the use of the following filters:

1. reading of the title: the article is selected if the title indicates a study that is related to virtual reality or the elderly;

2. reading of the abstract: the article is selected if the abstract presents a study that involves older people using a virtual reality technology;

3. reading of the full article: the article is selected if it answers at least two of the three research questions.

Doubts were solved by discussions involving all the authors of this paper, during face-to-face meetings.

\section{Quality assessment}

In order to be approved, an article must answer at least two of the three research questions. In general, every scientific article presents the purpose of the study. So, to ensure that at least SQ1.2 or SQ1.3 was answered, we considered RQ1 answered if at least two of its specific questions were answered. RQ2 was considered answered if at least one of its specific questions was answered.

\section{Data extraction}

The information was extracted from the articles exactly as written by the authors. The data extracted from each article were: publication year, title, publication title (journal or conference), keywords, full reference, answers to the research questions.

\section{RESULTS}

This section presents the results after applying the search filters described in Section 3. Table 1 presents an overview of the search results, after using each of the SLR filters. The first filter ("Search String") returned 264 articles from ACM Digital Library, IEEE Digital Library, Science Direct, and Google Scholar. As a final result of the search, 63 articles were obtained from the bases selected for the research. Many of these articles were related with rehabilitation and health. Tables 2, 3, 4, 5 and 6 show the lists of selected articles as well as some information extracted from them: objective, technology and year.

In the following subsections, we present the answers to our research questions.

\section{Which are the characteristics of the studies about the use of virtual reality by older users?}

The following subsections describe the information collected for the first research question.

What are the objectives of the studies? In general, the studies were related to subjects such as health, rehabilitation and well-being. Some studies were related to the mobility or bodily aspects of the elderly, including falls (Giotakos, Tsirgogianni, and Tarnanas 2007; Mirelman et al. 2011; Singh et al. 2011; Mirelman et al. 2016; Lim et al. 2017; Suárez, Suárez, and Lavinsky 2006; Nyberg et al. 2005; Kamińska et al. 2018), balance (Anson et al. 2018; Kim et al. 2013; de Vries et al. 2018; Park and Yim 2016; Hsieh et al. 2013; Park, Kim, and Lee 2015; Cho, Hwangbo, and Shin 2014; Lee and Song 2012), exercise (Bruun-Pedersen et al. 2014; Eisapour et al. 2018; Sáenz-de Urturi and Santos 2018; Lee et al. 2015; Tsuda et al. 2016; dos Santos et al. 2015; Klinger et al. 2012), postural control (Chang et al. 2016; Bourrelier et al. 2016; Arias et al. 2012), motor learning (Mendes et al. 2012), rehabilitation on upper extremity function (Lee et al. 2016), and kinematic responses (Gurses, Kenyon, and Keshner 2011).

Many studies were related to psychological or cognitive issues, including shifting of attention (Carelli et al. 2008), memory (Chapoulie et al. 2014; Plancher, Nicolas, and Piolino 2008; Ouellet et al. 2018; Plancher et al. 2012; 
Table 1: Number of selected articles

\begin{tabular}{|l|r|r|r|r|r|}
\hline \multirow{2}{*}{ Filter } & \multicolumn{5}{|c|}{ Number of Articles } \\
\cline { 2 - 6 } & ACM & IEEE & $\begin{array}{c}\text { Science } \\
\text { Direct }\end{array}$ & $\begin{array}{c}\text { Google } \\
\text { Scholar }\end{array}$ & Total \\
\hline Search String & 28 & 65 & 90 & 81 & 264 \\
\hline Title & 26 & 63 & 30 & 75 & 194 \\
\hline Abstract & 20 & 45 & 18 & 31 & 114 \\
\hline Full Reading & 9 & 15 & 16 & 23 & 63 \\
\hline
\end{tabular}

Table 2: ACM Digital Library - list of selected articles

\begin{tabular}{|l|l|l|l|}
\hline \multicolumn{1}{|c|}{ Objective } & \multicolumn{1}{|c|}{ Technology } & Year & \multicolumn{1}{c|}{ Ref } \\
\hline $\begin{array}{l}\text { Improvement of kitchen environment us- } \\
\text { ability }\end{array}$ & $\begin{array}{l}\text { AR and VR based } \\
\text { technologies }\end{array}$ & 2012 & (Ceccacci, Germani, and Mengoni 2012) \\
\hline Wayfinding design in healthcare facilities & Video projector & 2010 & (Lee 2010) \\
\hline Episodic memory assessment & Video projector & 2008 & (Plancher, Nicolas, and Piolino 2008) \\
\hline $\begin{array}{l}\text { Cognitive training game with participatory } \\
\text { design }\end{array}$ & $\begin{array}{l}\text { VR for mobile de- } \\
\text { vices }\end{array}$ & 2015 & (Votis et al. 2015) \\
\hline $\begin{array}{l}\text { Compare the risk and fear of falls pre } \\
\text { and post intervention using virtual reality } \\
\text { games }\end{array}$ & Wii balance board & 2011 & (Singh et al. 2011) \\
\hline $\begin{array}{l}\text { Design serious games for older adults with } \\
\text { dementia }\end{array}$ & HMD & 2018 & (Eisapour et al. 2018) \\
\hline $\begin{array}{l}\text { Investigate the design and use of virtual } \\
\text { avatars among older adults }\end{array}$ & HMD & 2018 & (Carrasco Zuffi 2018) \\
\hline $\begin{array}{l}\text { Virtual reality exercise for older adults liv- } \\
\text { ing with dementia }\end{array}$ & HMD & 2015 & (Eisapour et al. 2018) \\
\hline $\begin{array}{l}\text { Develop a personalized exergame aimed to } \\
\text { engage older adults }\end{array}$ & Kinect & (Sáenz-de Urturi and Santos 2018) \\
\hline
\end{tabular}

Optale et al. 2010; Jebara et al. 2014; Mohammadi, Kargar, and Hesami 2018), improve cognition (Park and Yim 2016; Serino et al. 2014; Klinger et al. 2012; Intraraprasit, Sunhem, and Jinjakam 2018), spatial orientation (Morganti and Riva 2011), psychomotor performance (Tarnanas, Mouzakidis, and Schlee 2013), executive functions (Yeh et al. 2012), deterioration in perceptual and cognitive function (Mitobe, Suzuki, and Yoshimura 2012), dementia (Liappas et al. 2018), and cognitive training game with participatory design (Votis et al. 2015). There were also a study about Positive mood induction (Baños et al. 2012) and decisionmaking procedure (Lin, Jeng, and Yeh 2018).

There are also studies about technological inclusion to "empower senior citizens to gain more control over their personal well-being" (Fernández et al. 2017), technology rejection criteria (Coldham and Cook 2017), and other studies about driving (Lithfous et al. 2014) and safe street-crossing (Maillot et al. 2017).

Other studies dealt with more diverse subjects involving user interface, behavior and design. For example, an evaluation of "the use of an immersive virtual reality (VR), a mouse and a touchscreen for one directional pointing, multi-directional pointing, and dragging-and-dropping tasks involving targets of smaller and larger widths" (Chen and Or 2017), an improvement of kitchen environment usability (Ceccacci, Germani, and Mengoni 2012), serious games design (Eisapour et al. 2018; Ahmed et al. 2018; Levy et al. 2016), design and use of virtual avatars (Carrasco Zuffi 2018), satisfaction in $360^{\circ}$ travel media (Srifar 2018), evaluation of complex environments exploration capacity (Morganti et al. 2009), and examine the usability of a newly designed virtual reality environment (Fong et al. 2010).

What were the data analysis procedures? Among the 63 selected studies, 59 presented the adopted method of data analysis.

The majority of the studies used statistical methods in their analyzes. 35 studies used only statistical analysis (Chang et al. 2016; Gurses, Kenyon, and Keshner 2011; Fernández et al. 2017; Mirelman et al. 2011; Mitobe, Suzuki, and Yoshimura 2012; Morganti and Riva 2011; Yeh et al. 2012; Singh et al. 2011; Sáenz-de Urturi and Santos 2018; Intraraprasit, Sunhem, and Jinjakam 2018; Ahmed et al. 2018; Liappas et al. 2018; de Vries et al. 2018; Kim et al. 2013; Mendes et al. 2012; Lee et al. 2016; Ouellet et al. 2018; Maillot et al. 2017; Mirelman et al. 2016; Tsuda et al. 2016; Park and Yim 2016; Morganti et al. 2009; 
dos Santos et al. 2015; Lithfous et al. 2014; Serino et al. 2014; Hsieh et al. 2013; Klinger et al. 2012; Levy et al. 2016; Benoit et al. 2015; Suárez, Suárez, and Lavinsky 2006; Kamińska et al. 2018; Park, Kim, and Lee 2015; Cho, Hwangbo, and Shin 2014; Fong et al. 2010; Lee and Song 2012).

Some authors specified the specific statistical analysis used. For example, Giotakos, Tsirgogianni, and Tarnanas (2007) and Tarnanas, Mouzakidis, and Schlee (2013) used MANOVA (multivariate analysis of variance). Lim et al. (2017), Plancher et al. (2012), and Lee et al. (2015) used ANCOVA (analysis of covariance). Ten studies used ANOVA (analysis of variance) (Chen and Or 2017; Lee 2010; Plancher, Nicolas, and Piolino 2008; Bourrelier et al. 2016; Anson et al. 2018; Baños et al. 2012; Optale et al. 2010; Jebara et al. 2014; Mohammadi, Kargar, and Hesami 2018; Arias et al. 2012).

Seven studies used only qualitative evaluation (BruunPedersen et al. 2014; Caggianese, Gallo, and Pietro 2014; Carrasco Zuffi 2018; Coldham and Cook 2017; Eisapour et al. 2018; Srifar 2018; Lin, Jeng, and Yeh 2018). Other two studies used used both qualitative and statistical approaches in their analyses (Carelli et al. 2008; Chapoulie et al. 2014).

Which virtual reality technology was applied? This section presents the technologies used in the selected studies, which varied a lot. Many of the studies used some motion capture technology (Caggianese, Gallo, and Pietro 2014; Chang et al. 2016; Chen and Or 2017), (Gurses, Kenyon, and Keshner 2011), (Mirelman et al. 2011), (Mitobe, Suzuki, and Yoshimura 2012), (Tarnanas, Mouzakidis, and Schlee 2013), (Yeh et al. 2012), (Mirelman et al. 2016), (Maillot et al. 2017), (Ahmed et al. 2018). Wii balance board was used in four studies (Singh et al. 2011; Lim et al. 2017; Mendes et al. 2012; de Vries et al. 2018), while other five studies used Kinect (Sáenz-de Urturi and Santos 2018; Ahmed et al. 2018; Lee et al. 2016; 2015; Kim et al. 2013).

Two of the studies used computer monitors to display virtual environments: (Caggianese, Gallo, and Pietro 2014) and (Carelli et al. 2008). There were also many works that considered projectors as a virtual reality technology to display the virtual environments (Chapoulie et al. 2014; Chen and Or 2017; Lee 2010; Mirelman et al. 2011; Mitobe, Suzuki, and Yoshimura 2012; Plancher, Nicolas, and Piolino 2008; Plancher et al. 2012; Maillot et al. 2017).

Head mounted displays (HMD) were used in 15 studies (Yeh et al. 2012; Fernández et al. 2017; Tarnanas, Mouzakidis, and Schlee 2013; Yeh et al. 2012; Eisapour et al. 2018; Carrasco Zuffi 2018; Eisapour et al. 2018; Intraraprasit, Sunhem, and Jinjakam 2018; Liappas et al. 2018; Ahmed et al. 2018; Coldham and Cook 2017; Ouellet et al. 2018).

Several other technologies can be found in the selected articles: chair-based exercise bike (Bruun-Pedersen et al. 2014), touch screen (Baños et al. 2012), TV screen (Anson et al. 2018), and NVidia 3D Vision Pro with special 3D glasses (Bourrelier et al. 2016).

Figure 1 presents the technologies used in the experiments reported in the selected articles.
How VR impacts on the experience of older users?

The following subsections describe the information collected to answer the second research question.

What design characteristics should be considered for this target audience? According to Bruun-Pedersen et al. (2014), the outdoor virtual environments for elderly should include more life and diversity, adding elements such as trees, wind, water, climate changes, animals, and events. These elements inspire exploration and help to avoid the feeling of static environment.

Metaphors are also important to make interaction more intuitive (Caggianese, Gallo, and Pietro 2014), such as using the same movements that are necessary in real life to interact with virtual objects.

Training and better virtual interaction design, such as more effective feedback, might improve older people's performance in using VR" (Chen and Or 2017). Besides, (Singh et al. 2011) concluded that "the environment and activities in the games should also be from daily life" and the "customization of physical parameters for each user" make the game intuitive and easy to play for the participants.

In Chapoulie et al. (2014), the authors stated that the physical setup they used for reminiscence therapy, such as a chair or a bench during testing, is well suited to the public with limited mobility. In addition, the authors mentioned the usefulness of VR for cognitive memory processes.

"Diminished capacity to attend to more than one task during postural demands has been cited as a causative factor for instability in the elderly" (Gurses, Kenyon, and Keshner 2011).

The participants of (Fernández et al. 2017) "perceived new VR technologies as interesting options through which to receive information more easily and in a more appealing format. The format was considered more appealing because video content and animations were used to complement written text".

The results presented in Morganti and Riva (2011) revealed that "only Alzheimer's patients require more time in the execution of wayfinding when an allocentric map of the environment was provided to them".

The findings of Eisapour et al. (2018) "contradict previous studies that suggested that older adults will prefer to create avatars different to their real bodies". Some participants wanted to create enhanced version of themselves and "two participants created avatars as companions that represented persons from their past".

Sáenz-de Urturi and Santos (2018) reported several recommendations: avoid tasks that requires head motion, keep visual targets in the front field of view, use verbal instructions, use a calibration process to adjust the required range of motion for each individual and interactions with virtual objects without using any buttons on the control interface.

Besides, the quality of the audio should properly match the rich 3D visual qualities of the VR environment (Liappas et al. 2018).

On its turn, Srifar (2018) showed that "the image displayed must not move too fast to prevent dizziness and improve comfort of the target consumers and is highly rec- 


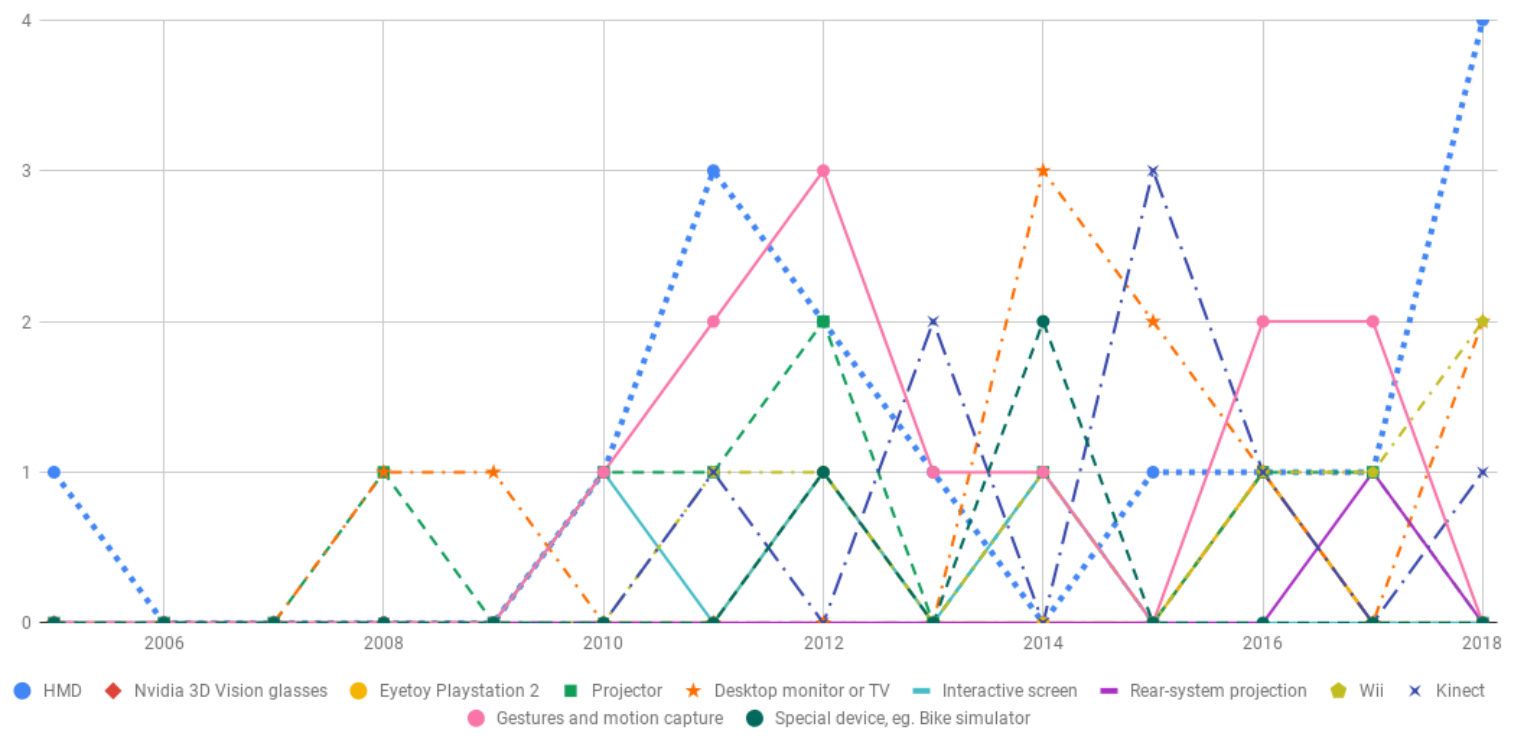

Figure 1: Technologies

ommended to implement a function to customize movement rate for the customer". Concerning image and sound quality, they stated that "the resolution of the display should be high and if the target consumers have visibility problems, they would use eyeglasses too to achieve best experience". The sound must be stereo so that the user recognize the direction of the sound.

Klinger et al. (2012) suggest "increasing the accessibility of the all application by improving contrasts by using raw colors and increasing the sizes of some elements" and "improve the motivation of users adding difficulty levels, and make the virtual environments living by adding people, animations (traffic flow for cities, people on the beach for seaside)". The authors also suggest that involving elderly people into the design process will allow the designers and developers to better fit their needs and expectations.

What was the experience of the older users regarding the use of VR? This section presents the experience of the older users regarding the use of VR in the selected articles. Even though user experience does not depend only on the hardware/device used, but also on the application, the information collected may be important for extracting values, perceptions and feelings from the elderly in relation to the use of virtual reality. This can help in the development of virtual reality applications for the older people.

Some studies presented notes from observations of older people and their familiar context. For example, the application developed for the study of Bruun-Pedersen et al. (2014) created several associations with past experiences. In addition, the study collected several feelings of the participants. One of them "described that the Virtual Environment (VE) provided a sense of accomplishment that she did not have with the conventional manuped exercise". The possibility of exercising while traveling through the VE provided a sense of purpose and happiness, which indicated to the authors an intrinsic motivation that was not present in the regular exercise.

Chapoulie et al. (2014) also noted that familiar environments have great emotional value for the elderly population. Besides, the participants of the study felt the experience as quite stimulating and interesting.

In the study conducted by Srifar (2018), the participants who have watched $360^{\circ}$ virtual reality travel media have enjoyed the experience. They felt like actually traveling to another place. Although the dizziness made some of them refuse to watch the media again, almost all of them were interested and wanted to travel to other places too.

Some participants of the study (Fernández et al. 2017) "expressed the desire to once again attend cultural events or locations that they had already visited in their lives", which showed to the authors of the study that "the emotional impact of being able to take fully immersive digital journeys to these sites of interest was rated extremely highly by participants".

Other studies had more focused reports about the interactivity of their applications. The analysis of Votis et al. (2015) "showed that elderly people find it very useful to navigate" in the game "environments in a 'click-and-go' fashion through respective visual aids, given that the aids are adequately intuitive".

Singh et al. (2011) stated that all participants were willing to continue working with the HMD-VR game and no one experienced problems with accessibility or while observing objects, which for the authors meant that the goals of the game were clear to participants. The participants of the study (Ahmed et al. 2018) had high acceptance too, although some participants did not understand the capabilities 
of VR in order to adopt it for everyday use.

In the study of Liappas et al. (2018), some participants stated that the headset was too heavy and expressed the view that VR was only for games and only for younger people.

The participants of Maillot et al. (2017) have been anxious before the experiment.

Besides, in the study of Park and Yim (2016), some participants felt dizzy from being exposed to the 3D environments.

Finally The authors of Lee and Song (2012) stated that "jumping and balancing on a beam in the boot camp game were tasks participants were unable to do in the real world, but they could follow the motions in a free and safe way in the virtual world".

\section{What are the suggestions for future work?}

Many of the selected works suggest improvements with the objective of increasing the accuracy of the method used and the validity of the research. For example, it was suggested to carry out studies with larger samples and with different configurations, to confirm previous results (Giotakos, Tsirgogianni, and Tarnanas 2007; Plancher, Nicolas, and Piolino 2008; Yeh et al. 2012; Jebara et al. 2014; Mohammadi, Kargar, and Hesami 2018; Arias et al. 2012; Lin, Jeng, and Yeh 2018; Levy et al. 2016; Optale et al. 2010). Other studies considered larger periods (BruunPedersen et al. 2014; Eisapour et al. 2018; Intraraprasit, Sunhem, and Jinjakam 2018; Suárez, Suárez, and Lavinsky 2006), while some studies considered both larger periods and samples (Lee et al. 2015; dos Santos et al. 2015; Mirelman et al. 2016; Maillot et al. 2017; Anson et al. 2018; Park, Kim, and Lee 2015).

Several studies suggested enhancing their applications to be more suitable for elderly or get different results: (Caggianese, Gallo, and Pietro 2014; Chapoulie et al. 2014; Kim et al. 2013; Bourrelier et al. 2016; Nyberg et al. 2005; Carrasco Zuffi 2018; Lee et al. 2016; Ahmed et al. 2018). Coldham and Cook (2017) suggested interviews in other countries to take a broader view, Kamińska et al. (2018) wanted to conduct experiments with participants of different profile and Baños et al. (2012) proposed to identify appropriate dosage of training durations.

Finally, there were studies with different proposals for future work. In Chen and Or (2017), the authors stated that "given that the factors affecting user performance in basic operations with VR are not yet well understood, aspects such as subjective preference, perceived exertion or submovement should be further examined in future studies". Another is to "provide an analysis of senior citizens' perceptions of their mastery of technology and confidence when using technology against their actual mastery of the technology" (Fernández et al. 2017). Besides, Plancher, Nicolas, and Piolino (2008) suggested their tool "opens up a large field of future investigations into episodic memory evaluation as well as rehabilitation".

\section{DiscuSSION}

The Systematic Literature Review allowed us to identify a concentration of studies in the health area and a low number of studies in other areas, such as education and entertainment. Other issues that can bring great contributions are related to the requirements of virtual reality entertainment software aimed at the elderly, or hardware requirements so that devices can be adapted to the physical and cognitive needs of the elderly users.

The devices used in the studies were varied. Only 15 studies reported the use of HMD, the best known device for immersive virtual reality. In addition, projectors or computer screens were considered a virtual reality technology in some studies. Several studies used motion capture technology as a means of interaction within the game or to collect data.

We also retrieved a small number of studies using qualitative methods. Qualitative research is important to understand a question or phenomenon in more depth. In a more recent area such as virtual reality, qualitative research could bring good contributions for the development of applications for older people.

With the information about the design characteristics and user experience related to the selected studies, it was possible to identify some elements to consider in experiments and also in the development of virtual reality applications for the elderly:

- Use larger-than-usual visual elements in the interface

- Consider the use of lighter equipment

- Use interaction with the body

- Consider the mobility problems of older people

- Offer options for the application to adapt to the particular characteristics of each user (such as customization of physical parameters and customization of movement rate)

- Use familiar environments that could be associated with past experiences.

- Use same movements that are necessary in real life to interact with virtual objects

- Avoid tasks that require the user to move the head quickly or images that move too fast in order to prevent dizziness

- Keep visual targets in the front field of view

- Use verbal instructions

- Use a calibration process to adjust the required range of motion for each individual

- Use high resolution on the display

- Use stereo sound

- Match the quality of the audio properly with the rich 3D visual qualities of the VR environment

- Perform a preparation session with the participants before usage of VR equipment

- Improve contrast by using raw colors

- Provide landmark-based encoding instructions

- Involve elderly people into the design process 
Table 3: IEEE Digital Library - list of selected articles

\begin{tabular}{|c|c|c|c|}
\hline Objective & Technology & Year & Ref \\
\hline Investigate the reduction of fear of falling & No information & 2007 & $\begin{array}{l}\text { (Giotakos, Tsirgogianni, and Tarnanas } \\
\text { 2007) }\end{array}$ \\
\hline Rehabilitation of shifting of attention & $\begin{array}{l}\text { Desktop monitor for } \\
\text { VR }\end{array}$ & 2008 & (Carelli et al. 2008) \\
\hline Evaluate executive functions and memory & $\begin{array}{l}\text { HMD and motion } \\
\text { capture technology }\end{array}$ & 2012 & (Yeh et al. 2012) \\
\hline $\begin{array}{l}\text { Investigate the use of VR technology as } \\
\text { part of exercise experience }\end{array}$ & $\begin{array}{l}\text { Chair-based exercise } \\
\text { bike and interactive } \\
\text { screen-based virtual } \\
\text { environment }\end{array}$ & 2014 & (Bruun-Pedersen et al. 2014) \\
\hline Presentation of cultural artefacts & $\begin{array}{l}\text { High-resolution } \\
\text { monitor and gestures } \\
\text { sensor. }\end{array}$ & 2014 & (Caggianese, Gallo, and Pietro 2014) \\
\hline $\begin{array}{l}\text { Reveal the elderly people about their dete- } \\
\text { rioration in perceptual and cognitive func- } \\
\text { tion }\end{array}$ & $\begin{array}{l}\text { Projector and motion } \\
\text { capture device }\end{array}$ & 2012 & (Mitobe, Suzuki, and Yoshimura 2012) \\
\hline $\begin{array}{l}\text { Determine what kind of cognitive and psy- } \\
\text { chomotor performance is associated with } \\
\text { functional impairment in activities of daily } \\
\text { living }\end{array}$ & $\begin{array}{l}\text { HMD and motion } \\
\text { capture device }\end{array}$ & 2013 & (Tarnanas, Mouzakidis, and Schlee 2013) \\
\hline Understanding the postural control & $\begin{array}{l}\text { Motion capture de- } \\
\text { vice }\end{array}$ & 2016 & (Chang et al. 2016) \\
\hline Reminiscence therapy & Projectors & 2014 & (Chapoulie et al. 2014) \\
\hline Rehabilitation of spatial orientation & VR technology & 2011 & (Morganti and Riva 2011) \\
\hline $\begin{array}{l}\text { Investigate if VR can be applied to ad- } \\
\text { dress the multifaceted deficits associated } \\
\text { with fall risk }\end{array}$ & $\begin{array}{l}\text { Projector and motion } \\
\text { capture device }\end{array}$ & 2011 & (Mirelman et al. 2011) \\
\hline $\begin{array}{l}\text { Behavior analysis to design efficient } \operatorname{cog}- \\
\text { nitive training }\end{array}$ & HMD & 2011 & $\begin{array}{l}\text { (Intraraprasit, Sunhem, and Jinjakam } \\
\text { 2018) }\end{array}$ \\
\hline $\begin{array}{l}\text { Perceive technological barriers and needs } \\
\text { of people suffering from dementia }\end{array}$ & HMD & 2011 & (Liappas et al. 2018) \\
\hline $\begin{array}{l}\text { Practical idea of serious games for elderly } \\
\text { patients }\end{array}$ & $\begin{array}{l}\text { HMD Oculus Rift, } \\
\text { Leap Motion and } \\
\text { Kinect }\end{array}$ & 2011 & (Ahmed et al. 2018) \\
\hline Examine technology rejection criteria & HMD HTC Vive & 2017 & (Coldham and Cook 2017) \\
\hline
\end{tabular}


Table 4: Science Direct - list of selected articles

\begin{tabular}{|c|c|c|c|}
\hline Objective & Technology & Year & Ref \\
\hline $\begin{array}{l}\text { Evaluation of interface and behavior of an } \\
\text { immersive virtual reality }\end{array}$ & $\begin{array}{l}\text { Projector, motion } \\
\text { capture device }\end{array}$ & 2017 & (Chen and Or 2017) \\
\hline $\begin{array}{l}\text { Examination of time-varying kinematic re- } \\
\text { sponses }\end{array}$ & $\begin{array}{l}\text { Motion capture de- } \\
\text { vice }\end{array}$ & 2010 & (Gurses, Kenyon, and Keshner 2011) \\
\hline $\begin{array}{l}\text { Empower senior citizens to gain more con- } \\
\text { trol to improve well-being }\end{array}$ & HMD & 2016 & (Fernández et al. 2017) \\
\hline $\begin{array}{l}\text { Treadmill training to reduce fall risk in } \\
\text { older adults }\end{array}$ & $\begin{array}{l}\text { motion-capture cam- } \\
\text { era and large screen }\end{array}$ & 2016 & (Mirelman et al. 2016) \\
\hline $\begin{array}{l}\text { Comparison of individualized virtual real- } \\
\text { ity and group-based rehabilitation }\end{array}$ & Kinect & 2016 & (Lee et al. 2016) \\
\hline $\begin{array}{l}\text { Design training program for prevention of } \\
\text { falling in the elderly }\end{array}$ & Wii balance board & 2017 & (Lim et al. 2017) \\
\hline $\begin{array}{l}\text { Study the effect of virtual reality exercise } \\
\text { on quality of life in older women }\end{array}$ & $\begin{array}{l}\text { Kinect and monitor } \\
\text { screen }\end{array}$ & 2015 & (Lee et al. 2015) \\
\hline $\begin{array}{l}\text { Evaluate the learning, retention and trans- } \\
\text { fer of performance improvements }\end{array}$ & Wii balance board & 2012 & (Mendes et al. 2012) \\
\hline Positive mood induction & $\begin{array}{l}\text { Touch screen with in- } \\
\text { tegrated audio speak- } \\
\text { ers }\end{array}$ & 2012 & (Baños et al. 2012) \\
\hline Assessment of everyday memory & HMD & 2018 & (Ouellet et al. 2018) \\
\hline $\begin{array}{l}\text { Help older pedestrians make safer street- } \\
\text { crossing decisions }\end{array}$ & $\begin{array}{l}\text { Rear-system projec- } \\
\text { tion, 3D sound ren- } \\
\text { dering system, and } \\
\text { motion capture sys- } \\
\text { tem }\end{array}$ & 2017 & (Maillot et al. 2017) \\
\hline $\begin{array}{l}\text { Determine whether trunk motion treadmill } \\
\text { walking would improve over-ground bal- } \\
\text { ance }\end{array}$ & TV screen & 2018 & (Anson et al. 2018) \\
\hline $\begin{array}{l}\text { Assess the effects of exercise program on } \\
\text { hip muscle strength and balance control }\end{array}$ & Kinect & 2013 & (Kim et al. 2013) \\
\hline Engage Motor and Postural Abilities & $\begin{array}{l}\text { NVidia 3D Vision } \\
\text { Pro with special 3D } \\
\text { glasses }\end{array}$ & 2016 & (Bourrelier et al. 2016) \\
\hline Characterize episodic memory profiles & Video projector & 2012 & (Plancher et al. 2012) \\
\hline $\begin{array}{l}\text { Assess to which extent skiing games chal- } \\
\text { lenge balance }\end{array}$ & Wii balance board & 2018 & (de Vries et al. 2018) \\
\hline
\end{tabular}


Table 5: Google Scholar - list of selected articles - to be continued

\begin{tabular}{|c|c|c|c|}
\hline Objective & Technology & Year & Ref \\
\hline $\begin{array}{l}\text { Study satisfaction of elderly in } 360^{\circ} \text { virtual } \\
\text { reality travel media. }\end{array}$ & HMD & 2018 & (Srifar 2018) \\
\hline $\begin{array}{l}\text { Investigate the feasibility and safety of vir- } \\
\text { tual reality exercise intervention in patients } \\
\text { with hematologic malignancies receiving } \\
\text { chemotherapy }\end{array}$ & Wii Balance Board & 2016 & (Tsuda et al. 2016) \\
\hline $\begin{array}{l}\text { Improve cognition, muscle strength, and } \\
\text { postural balance }\end{array}$ & No information & 2016 & (Park and Yim 2016) \\
\hline $\begin{array}{l}\text { Evaluate complex environments explo- } \\
\text { ration capacity }\end{array}$ & Desktop & 2009 & (Morganti et al. 2009) \\
\hline $\begin{array}{l}\text { Analysis of virtual reality versus functional } \\
\text { training in fitness }\end{array}$ & Kinect & 2015 & (dos Santos et al. 2015) \\
\hline $\begin{array}{l}\text { Improve spatial learning and driving abili- } \\
\text { ties }\end{array}$ & Driving simulator & 2014 & (Lithfous et al. 2014) \\
\hline Assess deficit in the mental frame syncing & Computer monitor & 2014 & (Serino et al. 2014) \\
\hline $\begin{array}{l}\text { Build an information platform of interac- } \\
\text { tive scenarios, for practices and evaluation } \\
\text { on balance ability }\end{array}$ & Kinect & 2013 & (Hsieh et al. 2013) \\
\hline $\begin{array}{l}\text { Lessen cognitive decline and improve } \\
\text { memory functions }\end{array}$ & $\begin{array}{l}\text { HMD and motion } \\
\text { tracking sensor }\end{array}$ & 2010 & (Optale et al. 2010) \\
\hline $\begin{array}{l}\text { Design of virtual reality based physical and } \\
\text { cognitive stimulation exercises }\end{array}$ & $\begin{array}{l}\text { Bike interfaced with } \\
\text { computer }\end{array}$ & 2012 & (Klinger et al. 2012) \\
\hline $\begin{array}{l}\text { Study effects of enactment in episodic } \\
\text { memory }\end{array}$ & $\mathrm{PC}$ and large screen & 2014 & (Jebara et al. 2014) \\
\hline
\end{tabular}


Table 6: Google Scholar - list of selected articles (continued)

\begin{tabular}{|c|c|c|c|}
\hline Objective & Technology & Year & Ref \\
\hline $\begin{array}{l}\text { Study efficacy of virtual reality as- } \\
\text { sociated with serious games in el- } \\
\text { derly people }\end{array}$ & $\begin{array}{l}\text { EyeToy PlayStation } \\
2 \text { and video projec- } \\
\text { tor. }\end{array}$ & 2016 & (Levy et al. 2016) \\
\hline $\begin{array}{l}\text { Evaluate the acceptability of a VR } \\
\text { experience using the image-based } \\
\text { rendering virtual environment }\end{array}$ & Large screen & 2015 & (Benoit et al. 2015) \\
\hline $\begin{array}{l}\text { Assess postural control adaptation } \\
\text { quantitatively in unsteady elderly } \\
\text { patients at risk of falls in open } \\
\text { spaces }\end{array}$ & No information & 2006 & (Suárez, Suárez, and Lavinsky 2006) \\
\hline $\begin{array}{l}\text { Development of a virtual reality } \\
\text { system to study tendency of falling } \\
\text { among older people }\end{array}$ & HMD & 2005 & (Nyberg et al. 2005) \\
\hline $\begin{array}{l}\text { Assess the effectiveness of virtual } \\
\text { reality training in reducing the risk } \\
\text { of falls among elderly people }\end{array}$ & Kinect & 2018 & (Kamińska et al. 2018) \\
\hline $\begin{array}{l}\text { Examine the effects of virtual re- } \\
\text { ality game exercise on balance and } \\
\text { gait of the elderly }\end{array}$ & No information & 2015 & (Park, Kim, and Lee 2015) \\
\hline $\begin{array}{l}\text { Determine the effects of virtual } \\
\text { reality-based balance training on } \\
\text { balance of the elderly }\end{array}$ & Wii Balance Board & 2014 & (Cho, Hwangbo, and Shin 2014) \\
\hline $\begin{array}{l}\text { Examine the awareness, decision- } \\
\text { making procedure, and personal } \\
\text { values of the elderly with regard to } \\
\text { virtual reality leisure activities }\end{array}$ & Wii & 2018 & (Lin, Jeng, and Yeh 2018) \\
\hline $\begin{array}{l}\text { Examine the usability of a newly } \\
\text { designed virtual reality environ- } \\
\text { ment for training in the healthy } \\
\text { older persons }\end{array}$ & $\begin{array}{l}\text { VR-ATM (interac- } \\
\text { tive screen) }\end{array}$ & 2010 & (Fong et al. 2010) \\
\hline $\begin{array}{l}\text { Determine the allocentric and ego- } \\
\text { centric memory deficits }\end{array}$ & Desktop & 2018 & (Mohammadi, Kargar, and Hesami 2018) \\
\hline $\begin{array}{l}\text { Evaluate of repetitive rhythmic } \\
\text { movements in the elderly and } \\
\text { Parkinson's disease patients }\end{array}$ & HMD & 2012 & (Arias et al. 2012) \\
\hline $\begin{array}{l}\text { Investigate the effects of a virtual } \\
\text { reality exercise program on the bal- } \\
\text { ance of elderly persons with type } 2 \\
\text { diabetes }\end{array}$ & $\begin{array}{l}\text { EyeToy PlayStation } \\
2 \text { and motion- } \\
\text { tracking camera }\end{array}$ & 2012 & (Lee and Song 2012) \\
\hline
\end{tabular}




\section{Conclusions}

In this article we present the results of a systematic literature review with the objective of identifying the studies related to virtual reality focusing older users. We also presented a list of some elements that we consider important for the development of virtual reality applications focusing on older people.

Several studies used sensors to collect data during the experiments. However, some studies presented different technologies in relation to other well-known technologies for use with virtual reality, which leads to the hypothesis that the concept of virtual reality is not yet consolidated.

Considering the objectives of the articles selected, it is possible to identify the main applications of virtual reality for the older people, now and in the near future: healthcare, rehabilitation, prevention of fall, physical activity engagement, cognitive exercises, fun and virtual travels to faraway places.

Finally, the research considered only articles of published in the ACM, IEEE, Science Direct, and Google Scholar. Then, for future work, we propose to carry out studies from other publications to address the failures resulting from these limitations.

The contribution of this work is to provide information about the methods conducted on previous research, user experience and future work on virtual reality with older adults as participants in the studies. This information can help researchers plan their research methods, improve the reliability of their work, and design virtual reality applications focused in the elderly.

\section{ACKNOWLEDGEMENTS}

This study was financed in part by the Coordenação de Aperfeiçoamento de Pessoal de Nível Superior - Brasil (CAPES) - Finance Code 88887.149279/2017-00 and Pontifícia Universidade Católica de Minas Gerais (PUC Minas).

\section{REFERENCES}

[1] Ahmed, B.; Kim, D. H.; Hwang, Y.; and Park, S. 2018. Treatment of alzheimer's, cognitive, chronic pain rehabilitation, depression and anxiety disorders in one system for elderly using vr. In 2018 15th International Conference on Ubiquitous Robots (UR), 483-488.

[2] Anson, E.; Ma, L.; Meetam, T.; Thompson, E.; Rathore, R.; Dean, V.; and Jeka, J. 2018. Trunk motion visual feedback during walking improves dynamic balance in older adults: Assessor blinded randomized controlled trial. Gait \& Posture 62:342-348.

[3] Arias, P.; Robles-García, V.; Sanmartín, G.; Flores, J.; and Cudeiro, J. 2012. Virtual reality as a tool for evaluation of repetitive rhythmic movements in the elderly and parkinson's disease patients. PloS one 7(1):e30021.

[4] Baños, R.; Etchemendy, E.; Castilla, D.; GarcíaPalacios, A.; Quero, S.; and Botella, C. 2012. Positive mood induction procedures for virtual environments designed for elderly people. Interacting with Computers 24(3):131-138.

[5] Benoit, M.; Guerchouche, R.; Petit, P.-D.; Chapoulie, E.; Manera, V.; Chaurasia, G.; Drettakis, G.; and Robert, P. 2015. Is it possible to use highly realistic virtual reality in the elderly? a feasibility study with image-based rendering. Neuropsychiatric disease and treatment 11:557.

[6] Bourrelier, J.; Ryard, J.; Dion, M.; Merienne, F.; Manckoundia, P.; and Mourey, F. 2016. Use of a Virtual Environment to Engage Motor and Postural Abilities in Elderly Subjects With and Without Mild Cognitive Impairment (MAAMI Project). IRBM 37(2):75-80.

[7] Bruun-Pedersen, J. R.; Pedersen, K. S.; Serafin, S.; and Kofoed, L. B. 2014. Augmented exercise biking with virtual environments for elderly users: A preliminary study for retirement home physical therapy. In 2014 2nd Workshop on Virtual and Augmented Assistive Technology (VAAT), 23-27.

[8] Caggianese, G.; Gallo, L.; and Pietro, G. D. 2014. Design and preliminary evaluation of a touchless interface for manipulating virtual heritage artefacts. In 2014 Tenth Int. Conf. on Signal-Image Technology and Internet-Based Systems, 493-500.

[9] Carelli, L.; Morganti, F.; Weiss, P. L.; Kizony, R.; and Riva, G. 2008. A virtual reality paradigm for the assessment and rehabilitation of executive function deficits post stroke: Feasibility study. In 2008 Virtual Rehabilitation, 99-104.

[10] Carrasco Zuffi, R. 2018. Older adults designing avatars for socializing. In Proceedings of the 2018 ACM Conference Companion Publication on Designing Interactive Systems, DIS '18 Companion, 379-382. New York, NY, USA: ACM.

[11] Ceccacci, S.; Germani, M.; and Mengoni, M. 2012. User centred approach for home environment designing. In Proceedings of the 5th Int. Conf. on PErvasive Technologies Related to Assistive Environments, PETRA '12, 31:1-31:8. New York, NY, USA: ACM.

[12] Chang, C. J.; Chern, J. S.; Yang, T. F.; and Yang, S. W. 2016. Recognition of cortical modulation mechanism in elderly postural control under the computerized dynamic posturography. In 2016 IEEE 16th Int. Conf. on Bioinformatics and Bioengineering (BIBE), 286-288.

[13] Chapoulie, E.; Guerchouche, R.; Petit, P. D.; Chaurasia, G.; Robert, P.; and Drettakis, G. 2014. Reminiscence therapy using image-based rendering in vr. In 2014 IEEE Virtual Reality (VR), 45-50.

[14] Chen, J., and Or, C. 2017. Assessing the use of immersive virtual reality, mouse and touchscreen in pointing and dragging-and-dropping tasks among young, middleaged and older adults. Applied Ergonomics 65:437 - 448.

[15] Cho, G. H.; Hwangbo, G.; and Shin, H. S. 2014. The effects of virtual reality-based balance training on balance of the elderly. Journal of physical therapy science 26(4):615-617. 
[16] Coldham, G., and Cook, D. M. 2017. Vr usability from elderly cohorts: Preparatory challenges in overcoming technology rejection. In 2017 National Information Technology Conference (NITC), 131-135.

[17] de Vries, A. W.; Faber, G.; Jonkers, I.; Van Dieen, J. H.; and Verschueren, S. M. 2018. Virtual reality balance training for elderly: Similar skiing games elicit different challenges in balance training. Gait \& Posture 59:111-116.

[18] dos Santos, F. F.; Magalhães, L. H. V. N.; de Sousa, F. A. N.; de Oliveira Marques, C.; Torres, M. V.; and Leal, S. S. 2015. Analysis of virtual reality versus functional training in fitness for elderly women. ConScientiae Saúde 14(1):117.

[19] Eisapour, M.; Cao, S.; Domenicucci, L.; and Boger, J. 2018. Participatory design of a virtual reality exercise for people with mild cognitive impairment. In Extended $A b$ stracts of the 2018 CHI Conference on Human Factors in Computing Systems, CHI EA '18, CS15:1-CS15:9. New York, NY, USA: ACM.

[20] Fernández, M. D. M.; Hernández, J. D. S.; Gutiérrez, J. M.; Escuela, M. R. H.; and Fino, E. R. 2017. Using communication and visualization technologies with senior citizens to facilitate cultural access and selfimprovement. Computers in Human Behavior 66:329 344.

[21] Fong, K. N.; Chow, K. K.; Wong, A. K.; Yan, E. W.; $\mathrm{Ng}, \mathrm{S}$. S.; and Koo, K. 2010. Usability of a virtual reality environment in community facilities for assessment and training in persons with acquired brain injury or older people in hong kong.

[22] Giotakos, O.; Tsirgogianni, K.; and Tarnanas, I. 2007. A virtual reality exposure therapy (vret) scenario for the reduction of fear of falling and balance rehabilitation training of elder adults with hip fracture history. In 2007 Virtual Rehabilitation, 155-158.

[23] Gurses, S.; Kenyon, R.; and Keshner, E. 2011. Examination of time-varying kinematic responses to support surface disturbances. Biomedical Signal Processing and Control 6(1):85 - 93. Biomedical signal processing(Extended selected papers from the 7th IFAC Symposium on Modelling and Control in Biomedical Systems(MCBMS'09)).

[24] Hsieh, W.-M.; Chen, C.-C.; Wang, S.-C.; Chen, Y.L.; Hwang, Y.-S.; and Lai, J.-S. 2013. Combination of the kinect with virtual reality in balance training for the elderly. Engineering 5(10):171.

[25] Ijsselsteijn, W.; Nap, H. H.; de Kort, Y.; and Poels, K. 2007. Digital game design for elderly users. In Proceedings of the 2007 Conf. on Future Play, 17-22. New York, NY, USA: ACM.

[26] Intraraprasit, M.; Sunhem, W.; and Jinjakam, C. 2018. Interaction behavior of older adults with immersive virtual reality application for cognitive training. In $20183 \mathrm{rd}$ International Conference on Computer and Communication Systems (ICCCS), 506-510.
[27] Jebara, N.; Orriols, E.; Zaoui, M.; Berthoz, A.; and Piolino, P. 2014. Effects of enactment in episodic memory: a pilot virtual reality study with young and elderly adults. Frontiers in aging neuroscience 6:338.

[28] Kamińska, M. S.; Miller, A.; Rotter, I.; Szylińska, A.; and Grochans, E. 2018. The effectiveness of virtual reality training in reducing the risk of falls among elderly people. Clinical interventions in aging 13:2329.

[29] Kim, J.; Son, J.; Ko, N.; and Yoon, B. 2013. Unsupervised Virtual Reality-Based Exercise Program Improves Hip Muscle Strength and Balance Control in Older Adults: A Pilot Study. Archives of Physical Medicine and Rehabilitation 94(5):937-943.

[30] Kitchenham, B., and Charters, S. 2007. Guidelines for performing systematic literature reviews in software engineering. Technical Report EBSE 2007-001, Keele University and Durham University Joint Report.

[31] Klinger, E.; Martinet, E.; Lucas, A.; and Perret, D. 2012. Design of virtual reality based physical and cognitive stimulation exercises for elderly people. $10-12$.

[32] Lee, S. W., and Song, C. H. 2012. Virtual reality exercise improves balance of elderly persons with type 2 diabetes: a randomized controlled trial. Journal of Physical Therapy Science 24(3):261-265.

[33] Lee, M.; Son, J.; Kim, J.; and Yoon, B. 2015. Individualized feedback-based virtual reality exercise improves older women's self-perceived health: A randomized controlled trial. Archives of Gerontology and Geriatrics 61(2):154-160.

[34] Lee, M.; Son, J.; Kim, J.; Pyun, S.-B.; Eun, S.-D.; and Yoon, B. 2016. Comparison of individualized virtual reality- and group-based rehabilitation in older adults with chronic stroke in community settings: a pilot randomized controlled trial. European Journal of Integrative Medicine 8(5):738-746.

[35] Lee, S. 2010. Understanding wayfinding for the elderly using vr. In Proceedings of the 9th ACM SIGGRAPH Conf. on Virtual-Reality Continuum and Its Applications in Industry, VRCAI '10, 285-288. New York, NY, USA: ACM.

[36] Levy, F.; Leboucher, P.; Rautureau, G.; Komano, O.; Millet, B.; and Jouvent, R. 2016. Fear of falling: efficacy of virtual reality associated with serious games in elderly people. Neuropsychiatric disease and treatment 12:877.

[37] Liappas, N.; García-Betances, R. I.; Teriús-Padrón, J. G.; and Cabrera-Umpiérrez, M. F. 2018. Studying the technological barriers and needs of people with dementia: A quantitative study. In 2018 IEEE International Conference on Pervasive Computing and Communications Workshops (PerCom Workshops), 884-889.

[38] Lim, J.; Cho, J.-J.; Kim, J.; Kim, Y.; and Yoon, B. 2017. Design of virtual reality training program for prevention of falling in the elderly: A pilot study on complex versus balance exercises. European Journal of Integrative Medicine 15:64-67. 
[39] Lin, C.-S.; Jeng, M.-Y.; and Yeh, T.-M. 2018. The elderly perceived meanings and values of virtual reality leisure activities: A means-end chain approach. International journal of environmental research and public health 15(4):663.

[40] Lithfous, S.; Dufour, A.; Moessinger, M.; Bilz, L.; Sundby, C.; Pebayle, T.; and Després, O. 2014. Appropriate encoding strategies compensate for driving abilities in elderly individuals: A virtual reality study. Journal of the American Geriatrics Society 62(9):1795-1797.

[41] Lopez-Martinez, A.; Santiago-Ramajo, S.; Caracuel, A.; Valls-Serrano, C.; Hornos, M. J.; and RodriguezFortiz, M. J. 2011. Game of gifts purchase: Computerbased training of executive functions for the elderly. In Proceedings of IEEE 1st Int. Conf. on Serious Games and Applications for Health (SeGAH), 1-8.

[42] Maciel, A. C. C.; Guerra, R. O. 2005. Prevalência e fatores associados ao defícit de equilibrio em idosos. Brazilian Journal of Science and Movement 13:37-44.

[43] Maillot, P.; Dommes, A.; Dang, N.-T.; and Vienne, F. 2017. Training the elderly in pedestrian safety: Transfer effect between two virtual reality simulation devices. Accident Analysis \& Prevention 99:161-170.

[44] Mendes, F. A. d. S.; Pompeu, J. E.; Lobo, A. M.; da Silva, K. G.; Oliveira, T. d. P.; Zomignani, A. P.; and Piemonte, M. E. P. 2012. Motor learning, retention and transfer after virtual-reality-based training in Parkinson's disease - effect of motor and cognitive demands of games: a longitudinal, controlled clinical study. Physiotherapy 98(3):217-223.

[45] Mirelman, A.; Beer, N. R.; Dorffman, M.; Brozgul, M.; and Hausdorff, J. 2011. Treadmill training with virtual reality to decrease risk of falls in idiopathic fallers: A pilot study. In 2011 Int. Conf. on Virtual Rehabilitation, $1-4$.

[46] Mirelman, A.; Rochester, L.; Maidan, I.; Del Din, S.; Alcock, L.; Nieuwhof, F.; Rikkert, M. O.; Bloem, B. R.; Pelosin, E.; Avanzino, L.; Abbruzzese, G.; Dockx, K.; Bekkers, E.; Giladi, N.; Nieuwboer, A.; and Hausdorff, J. M. 2016. Addition of a non-immersive virtual reality component to treadmill training to reduce fall risk in older adults (V-TIME): a randomised controlled trial. The Lancet 388(10050):1170-1182.

[47] Mitobe, K.; Suzuki, M.; and Yoshimura, N. 2012. Development of pedestrian simulator for the prevention of traffic accidents involving elderly pedestrians. In 2012 Proceedings of SICE Annual Conf. (SICE), 1365-1368.

[48] Mohammadi, A.; Kargar, M.; and Hesami, E. 2018. Using virtual reality to distinguish subjects with multiplebut not single-domain amnestic mild cognitive impairment from normal elderly subjects. Psychogeriatrics 18(2):132-142.

[49] Morganti, F., and Riva, G. 2011. Spatial orientation decline in elderly population. In 2011 Int. Conf. on Virtual Rehabilitation, 1-2.
[50] Morganti, F.; Marrakchi, S.; Urban, P. P.; Iannoccari, G. A.; and Riva, G. 2009. A virtual reality based tool for the assessment of "survey to route" spatial organization ability in elderly population: preliminary data. Cognitive processing 10(2):257-259.

[51] NCBI. 2014. Most common causes of sight loss. http://goo.gl/Ijvlc2. Accessed 16 Dec 2013.

[52] Nyberg, L.; Lundin-Olsson, L.; Sondell, B.; Backman, A.; Holmlund, K.; Eriksson, S.; Stenvall, M.; Rosendahl, E.; Maxhall, M.; and Bucht, G. 2005. The development of a virtual reality system to study tendency of falling among older people. International Journal on Disability and Human Development 4(3):239-244.

[53] Optale, G.; Urgesi, C.; Busato, V.; Marin, S.; Piron, L.; Priftis, K.; Gamberini, L.; Capodieci, S.; and Bordin, A. 2010. Controlling memory impairment in elderly adults using virtual reality memory training: a randomized controlled pilot study. Neurorehabilitation and neural repair 24(4):348-357.

[54] Ouellet, É.; Boller, B.; Corriveau-Lecavalier, N.; Cloutier, S.; and Belleville, S. 2018. The Virtual Shop: A new immersive virtual reality environment and scenario for the assessment of everyday memory. Journal of Neuroscience Methods 303:126-135.

[55] Papalia, D. E., and Feldman, R. D. 2013. Desenvolvimento Humano. ISBN 9788580552171. Porto Alegre: ArtMed, 12 edition.

[56] Park, J., and Yim, J. 2016. A new approach to improve cognition, muscle strength, and postural balance in community-dwelling elderly with a 3-d virtual reality kayak program. The Tohoku journal of experimental medicine 238(1):1-8.

[57] Park, E.-C.; Kim, S.-G.; and Lee, C.-W. 2015. The effects of virtual reality game exercise on balance and gait of the elderly. Journal of physical therapy science 27(4):1157-1159.

[58] Plancher, G.; Tirard, A.; Gyselinck, V.; Nicolas, S.; and Piolino, P. 2012. Using virtual reality to characterize episodic memory profiles in amnestic mild cognitive impairment and Alzheimer's disease: Influence of active and passive encoding. Neuropsychologia 50(5):592-602.

[59] Plancher, G.; Nicolas, S.; and Piolino, P. 2008. Virtual reality as a tool for assessing episodic memory. In Proceedings of the 2008 ACM Symposium on Virtual Reality Software and Technology, VRST '08, 179-182. New York, NY, USA: ACM.

[60] Sáenz-de Urturi, Z., and Santos, O. C. 2018. User modelling in exergames for frail older adults. In Adjunct Publication of the 26th Conference on User Modeling, Adaptation and Personalization, UMAP ' 18, 83-86. New York, NY, USA: ACM.

[61] Serino, S.; Cipresso, P.; Gaggioli, A.; and Riva, G. 2014. Assessing the mental frame syncing in the elderly: a virtual reality protocol. Stud Health Technol Inform 199(153):7. 
[62] Singh, D. K. A.; Palaniswamy, V.; Raman, V. A. P.; Pearson, H.; Sien, B. P.; and Rajaratnam, B. S. 2011. Can exercises using virtual reality games reduce risk and fear of falls among older women? In Proceedings of the 5th International Conference on Rehabilitation Engineering \& Assistive Technology, i-CREATe '11, 21:1-21:4. Kaki Bukit TechPark II, Singapore: Singapore Therapeutic, Assistive \& Rehabilitative Technologies (START) Centre.

[63] Srifar, D. 2018. $360^{\circ}$ virtual reality travel media for elderly. arXiv preprint arXiv:1807.09074.

[64] Suárez, H.; Suárez, A.; and Lavinsky, L. 2006. Postural adaptation in elderly patients with instability and risk of falling after balance training using a virtual-reality system. International Tinnitus Journal 12(1):41.

[65] Tarnanas, I.; Mouzakidis, C.; and Schlee, W. 2013. Functional impairment in virtual-reality-dailyliving-activities as a defining feature of amnestic mci: Cognitive and psychomotor correlates. In 2013 Int. Conf. on Virtual Rehabilitation (ICVR), 27-34.

[66] Tcha-Tokey, K.; Loup-Escande, E.; Christmann, O.; and Richir, S. 2016. A questionnaire to measure the user experience in immersive virtual environments. In Proceedings of the 2016 Virtual Reality Int. Conf., VRIC '16, 19:1-19:5. New York, NY, USA: ACM.

[67] Tsuda, K.; Sudo, K.; Goto, G.; Takai, M.; Itokawa, T.; Isshiki, T.; Takei, N.; Tanimoto, T.; and Komatsu, T. 2016. A feasibility study of virtual reality exercise in elderly patients with hematologic malignancies receiving chemotherapy. Internal Medicine 55(4):347-352.

[68] Tullis, T., and Albert, W. 2008. Measuring the User Experience: Collecting, Analyzing, and Presenting Usability Metrics. San Francisco, CA, USA: Morgan Kaufmann Publishers Inc.

[69] Vasconcelos, A.; Silva, P. A.; Caseiro, J.; Nunes, F.; and Teixeira, L. F. 2012. Designing tablet-based games for seniors: The example of cogniplay, a cognitive gaming platform. In Proceedings of the 4th Int. Conf. on Fun and Games, FnG '12, 1-10. New York, NY, USA: ACM.

[70] Votis, K.; Giakoumis, D.; Vasileiadis, M.; Doumpoulakis, S.; Segkoyli, S.; and Tzovaras, D. 2015. Mobile cognitive training games for older adults with mild cognitive impairment. In Proceedings of the 17th Int. Conf. on Human-Computer Interaction with Mobile Devices and Services Adjunct, MobileHCI '15, 932-935. New York, NY, USA: ACM.

[71] World Health Organization. 2015. World report on ageing and health. World Health Organization.

[72] Yeh, S. C.; Chen, Y. C.; Tsai, C. F.; and Rizzo, A. 2012. An innovative virtual reality system for mild cognitive impairment: Diagnosis and evaluation. In 2012 IEEE-EMBS Conf. on Biomedical Engineering and Sciences, 23-27.

[73] Zarour, M., and Alharbi, M. 2017. User experience aspects and dimensions: Systematic literature review. Int. Journal of Knowledge Engineering 3:52-59. 